\title{
Validity of Continuous Pulse Oximetry Orders for Identification of Actual Monitoring Status in Bronchiolitis
}

\author{
Patrick W Brady, MD, MSc ${ }^{1,2,3 *}$, Amanda C Schondelmeyer, MD, MSc ${ }^{1,2,3}$, Christopher P Landrigan, MD, MPH ${ }^{4,5,6}$, Rui Xiao, PhD7, \\ Canita Brent, $\mathrm{MPH}^{8}$, Christopher P Bonafide, MD, MSCE $8,9,10,11$, for the Pediatric Research in Inpatient Settings (PRIS) Network
}

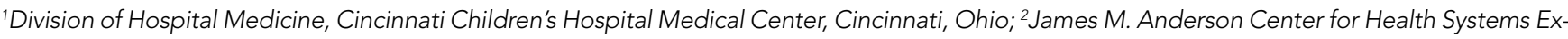
cellence, Cincinnati Children's Hospital Medical Center, Cincinnati, Ohio; ${ }^{3}$ Department of Pediatrics, University of Cincinnati College of Medicine, Cincinnati, Ohio; ${ }^{4}$ Division of General Pediatrics, Department of Pediatrics, Boston Children's Hospital, Boston, Massachusetts; ${ }^{5}$ Division of Sleep and Circadian Disorders, Departments of Medicine and Neurology, Brigham and Women's Hospital, Boston, Massachusetts; ${ }^{6} \mathrm{Harvard}$ Medical School, Boston, Massachusetts; 'Department of Biostatistics, Epidemiology, and Informatics, Perelman School of Medicine at the University of Pennsylvania, Philadelphia, Pennsylvania; ${ }^{8}$ Section of Pediatric Hospital Medicine, Children's Hospital of Philadelphia, Philadelphia, Pennsylvania; ${ }^{9}$ Department of Biomedical and Health Informatics, Children's Hospital of Philadelphia, Philadelphia, Pennsylvania; ${ }^{10} \mathrm{Center}$ for Pediatric Clinical Effectiveness, Children's Hospital of Philadelphia, Philadelphia, Pennsylvania; ${ }^{11}$ Department of Pediatrics, Perelman School of Medicine at the University of Pennsylvania, Philadelphia, Pennsylvania.
\end{abstract}

The accuracy of pulse oximetry monitor orders for identifying infants with bronchiolitis who are being continuously monitored is unknown. In this 56-hospital repeated cross-sectional study, investigators used direct bedside observation to determine continuous pulse oximetry monitor use and then assessed if an active continuous monitoring order was present in the electronic health record. Investigators completed 3,612 observations of infants aged 8 weeks to 23 months hospitalized with bronchiolitis and on room air.
Most monitored infants did not have an active monitoring order (sensitivity 49\% [95\% Cl, 41-57]). The positive predictive value of a monitoring order was $77 \%(95 \% \mathrm{Cl}, 72-82)$, and the negative predictive value was $69 \%(95 \% \mathrm{Cl}, 61-77)$. Teams intending to measure continuous pulse oximetry use should understand the limitations of using electronic health record orders as a stand-alone measure. Journal of Hospital Medicine 2020;15:665-668. (C) 2020 Society of Hospital Medicine

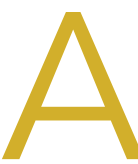

$s$ part of improvement collaboratives that aimed to reduce overuse of continuous pulse oximetry in children hospitalized with bronchiolitis, researchers used the presence of an active order for it as a proxy for the actual use of such monitoring. ${ }^{1,2}$ With use of this proxy, investigators on a national study documented a high burden of continuous oximetry overuse $(86.5 \%$ before quality improvement interventions and $45.5 \%$ after), ${ }^{1}$ but the validity of orders in representing actual monitoring practice is unknown. If the presence of an active pulse oximetry order accurately identifies infants on monitors, electronic health record data could inform epidemiologic estimates of monitoring overuse and measure the success of quality improvement and deimplementation interventions. Alternatively, if nurses commonly begin and/or discontinue pulse oximetry without updated orders, a pulse oximetry order would not be an accurate proxy, and additional data capture methods (eg, bedside observation or data capture from bedside monitors) would be needed.

*Corresponding Author: Patrick W Brady, MD, MSc; Email: patrick.brady@ cchmc.org; Telephone: 513-636-3635; Twitter: @patrickwbrady.

Published online first October 21, 2020.

Find additional supporting information in the online version of this article.

Received: December 19, 2020; Revised: April 3, 2020; Accepted: April 9, 2020

() 2020 Society of Hospital Medicine DOI 10.12788/jhm.3443
Understanding the validity of orders for detection of actual use is critical because continuous pulse oximetry monitoring is considered an overused practice in pediatric acute viral bronchiolitis, ${ }^{3}$ and national guidelines recommend against its use in low-risk hospitalized children. ${ }^{4,5}$ Continuous monitoring may identify trivial, self-resolving oxygen desaturation and its use is not associated with improved outcomes. ${ }^{6-9}$ When self-resolving desaturations are treated with additional supplemental oxygen, hospital stays may be unnecessarily prolonged. ${ }^{10}$ In order to reduce unnecessary continuous pulse oximetry use, measurement of the extent of the overused practice is necessary. In this 56-hospital study, ${ }_{1}^{11}$ we aimed to determine the validity of using active continuous pulse oximetry orders instead of bedside observation of actual monitor use.

\section{METHODS}

\section{Design}

In this multicenter, repeated cross-sectional study, investigators used direct bedside observation to determine continuous pulse oximetry monitor use and then assessed whether an active continuous monitoring order was present in the electronic health record. The study took place during one bronchiolitis season, December 1, 2018, through March 31, 2019.

\section{Setting and Patients}

Investigators at 56 freestanding children's hospitals, children's hospitals within general hospitals, and community hospitals in 
the Pediatric Research in Inpatient Settings (PRIS) Network collected data on infants aged 8 weeks to 23 months who were hospitalized with bronchiolitis. As this work was a substudy of the larger Eliminating Monitor Overuse study, only infants not currently receiving supplemental oxygen were included. ${ }^{11}$ Investigators observed eligible infants outside of the intensive care unit on general hospital medicine units. We excluded infants born premature (documented prematurity of $<28$ weeks' gestation or documented "premature" without a gestational age listed), as well as those with a home oxygen requirement, cyanotic congenital heart disease, pulmonary hypertension, tracheostomy, primary neuromuscular disease, immunodeficiency, or cancer.

\section{Data Collection}

Investigators used the electronic health record to identify eligible infants. Investigators entered patient rooms to confirm the infant was not on supplemental oxygen (hence confirming eligibility for the study) and determine if continuous pulse oximetry was actively in use by examining the monitor display for a pulse oximetry waveform. Investigators then confirmed if active orders for pulse oximetry were present in the patient's chart. Per study design, site investigators aimed to observe approximately half of eligible infants during the day (10 AM to 5 PM) and the other half during the night (11 PM to 7 AM).

\section{Analysis}

We excluded patients with conditional orders (eg, monitored only when certain conditions exist, such as when asleep) because of the time-varying and wide range of conditions that could be specified. Furthermore, conditional orders would not be useful as proxies to measure oximetry use because investigators would still need additional data (eg, bedside observation) to determine current monitoring status.

We calculated the sensitivity, specificity, positive predictive value (PPV), and negative predictive value (NPV) of active orders using the reference standard of direct bedside observation, as well as corresponding $95 \% \mathrm{Cls}$ that accounted for within-hospital clustering. We calculated these test characteristics overall and as stratified across four age groups: 8 weeks to 5 months, 6 months to 11 months, 12 months to 17 months, and 18 months to 23 months. We also calculated the test characteristics for each hospital. We decided a priori that a PPV and NPV of $80 \%$ would represent a reasonable threshold to use active orders as a proxy in multicenter research. For hospital-level analyses we included only hospitals with 60 or more total observations and more than 15 observations with active orders for PPV and more than 15 observations without active orders for NPV. We used Stata (StataCorp LLC, College Station, Texas) version 15.1 for analysis.

For US sites, the Institutional Review Board (IRB) at Children's Hospital of Philadelphia approved the study as the single reviewing IRB, and the remaining US sites established reliance agreements with the reviewing IRB. Research Ethics Boards at the Canadian sites (University of Calgary and The Hospital for Sick Children) also reviewed and approved the study. All sites granted waivers of consent, assent, parental permission, and HIPAA authorization.

\section{RESULTS}

Investigators completed 3,612 observations in 56 hospitals. This included 33 freestanding children's hospitals, 14 hospitals within large general hospitals, and 9 community hospitals. Of 3,612 completed observations, on 631 occasions (17\%) patients had conditional orders (eg, continuous monitoring only when sleeping) and were excluded from further analysis.

Most pulse oximetry-monitored infants did not have an active monitoring order ( 670 out of 1,309; sensitivity of $49 \%$ ). Test characteristics, stratified by age group, are presented in the Table. Across all observations, the overall PPV was $77 \%(95 \% \mathrm{Cl}$, $72-82)$, and the overall NPV was $69 \%(95 \% \mathrm{Cl}, 61-77)$. Variation of all test characteristics across age group was small (eg, the sensitivity ranged from $43 \%$ to $51 \%$ ).

With inclusion of only those hospitals with sufficient observations, hospital-level variation in the PPV and NPV of using active orders was substantial (PPV range of $48 \%$ to $96 \%$ and NPV range of $30 \%$ to $98 \%$ ). Only two hospitals had both a PPV and NPV for using monitor orders that exceeded the $80 \%$ threshold.

\section{DISCUSSION}

Active continuous pulse oximetry orders did not accurately represent actual monitoring status in this study. Monitoring orders alone frequently misrepresent true monitoring status and, as such, should be interpreted with caution in research or quality improvement activities. If more valid estimates of monitoring use and overuse are needed, potential measurement options include direct observation, as used in our study, as well as the use of more complex data streams such as the output of monitoring devices or pulse oximetry data in the electronic health record. In only two of the hospitals, using active continuous monitoring orders was a reasonable proxy for detecting actual monitor use. Monitoring orders could potentially be validly used for deimplementation efforts at those centers; other hospitals could consider targeted improvement efforts (eg, morning huddles examining the discordance between monitoring orders and monitoring status) to improve the accuracy of using continuous pulse oximetry orders.

We acknowledge several limitations of this study. Site investigators employed a convenience sampling approach, so it is possible that some investigators observed sicker or less sick infants. Although the PRIS network includes a geographically diverse group of North American hospitals, community hospitals were underrepresented in this study. Our results hence generalize more precisely to freestanding children's hospitals than to community hospitals. We did not observe infants currently on supplemental oxygen, so we do not know to what degree using orders is valid in that context. We did not collect data on why actual monitoring status differed from monitoring orders and hence cannot quantify to what extent different factors (eg, nurse belief that monitors are a safety net or infants inadvertently left on monitors after a spot check pulse oximetry reading) contributed to this discordance. Finally, our study only examined one electronic health record variable- the presence of an active 
TABLE. Test Characteristics of the Relationship Between Active Orders and Actual Pulse Oximetry Monitoring, Both Overall and as Stratified by Age

\begin{tabular}{|c|c|c|c|}
\hline Overall & Patient monitored & Patient unmonitored & \\
\hline Active order present & 639 & 192 & $\begin{array}{c}\text { PPV: } 77 \% \\
(95 \% \mathrm{Cl}, 72 \%-82 \%)\end{array}$ \\
\hline \multirow[t]{2}{*}{ Active order absent } & 670 & 1,480 & \multirow{2}{*}{$\begin{array}{c}\text { NPV: } 69 \% \\
(95 \% \mathrm{Cl}, 61 \%-77 \%)\end{array}$} \\
\hline & $\begin{array}{c}\text { Sensitivity: 49\% } \\
(95 \% \mathrm{Cl}, 41 \%-57 \%)\end{array}$ & $\begin{array}{c}\text { Specificity: } 89 \% \\
(95 \% \mathrm{Cl}, 85 \%-92 \%)\end{array}$ & \\
\hline $8 w k-5$ mo & Patient monitored & Patient unmonitored & \\
\hline \multirow[t]{2}{*}{ Active order present } & \multirow[t]{2}{*}{339} & \multirow[t]{2}{*}{76} & PPV: $82 \%$ \\
\hline & & & $(95 \% \mathrm{Cl}, 76 \%-88 \%)$ \\
\hline \multirow[t]{2}{*}{ Active order absent } & 330 & 695 & \multirow{2}{*}{$\begin{array}{c}\text { NPV: } 68 \% \\
(95 \% \mathrm{Cl}, 60 \%-76 \%)\end{array}$} \\
\hline & $\begin{array}{c}\text { Sensitivity: } 51 \% \\
(95 \% \mathrm{Cl}, 41 \%-60 \%)\end{array}$ & $\begin{array}{c}\text { Specificity: } 90 \% \\
\text { (95\% Cl, 87\%-93\%) }\end{array}$ & \\
\hline $6 \mathrm{mo}-11 \mathrm{mo}$ & Patient monitored & Patient unmonitored & \\
\hline Active order present & 172 & 62 & $\begin{array}{c}\text { PPV: } 74 \% \\
\text { (95\% Cl, 67\%-80\%) }\end{array}$ \\
\hline \multirow[t]{2}{*}{ Active order absent } & 182 & 406 & \multirow{2}{*}{$\begin{array}{c}\text { NPV: } 69 \% \\
(95 \% \mathrm{Cl}, 60 \%-78 \%)\end{array}$} \\
\hline & $\begin{array}{c}\text { Sensitivity: } 49 \% \\
(95 \% \mathrm{Cl}, 39 \%-58 \%)\end{array}$ & $\begin{array}{c}\text { Specificity: } 87 \% \\
\text { (95\% Cl, 83\%-91\%) }\end{array}$ & \\
\hline $12 \mathrm{mo}-17 \mathrm{mo}$ & Patient monitored & Patient unmonitored & \\
\hline Active order present & 80 & 35 & $\begin{array}{c}\text { PPV: } 70 \% \\
(95 \% \mathrm{Cl}, 60 \%-79 \%)\end{array}$ \\
\hline \multirow[t]{2}{*}{ Active order absent } & 104 & 247 & \multirow{2}{*}{$\begin{array}{c}\text { NPV: } 70 \% \\
(95 \% \mathrm{Cl}, 62 \%-78 \%)\end{array}$} \\
\hline & $\begin{array}{c}\text { Sensitivity: } 43 \% \\
(95 \% \mathrm{Cl}, 33 \%-54 \%)\end{array}$ & $\begin{array}{c}\text { Specificity: } 88 \% \\
(95 \% \mathrm{Cl}, 82 \%-93 \%)\end{array}$ & \\
\hline $18 \mathrm{mo}-23 \mathrm{mo}$ & Patient monitored & Patient unmonitored & \\
\hline Active order present & 48 & 19 & $\begin{array}{c}\text { PPV: } 72 \% \\
(95 \% \mathrm{Cl}, 58 \%-85 \%)\end{array}$ \\
\hline \multirow[t]{2}{*}{ Active order absent } & 54 & 132 & \multirow{2}{*}{$\begin{array}{c}\text { NPV: } 71 \% \\
(95 \% \mathrm{Cl}, 61 \%-81 \%)\end{array}$} \\
\hline & $\begin{array}{c}\text { Sensitivity: } 47 \% \\
(95 \% \mathrm{Cl}, 35 \%-59 \%)\end{array}$ & $\begin{array}{c}\text { Specificity: } 87 \% \\
(95 \% \mathrm{Cl}, 80 \%-95 \%)\end{array}$ & \\
\hline
\end{tabular}

Abbreviations: mo, months; NPV, negative predictive value; PPV, positive predictive value; wk, weeks.

order. It may be that other variables in the health record (eg, minute-by-minute pulse oximetry values in a vital sign flowsheet) are much better proxies of actual continuous monitor use.

\section{CONCLUSION}

Using an active order for continuous pulse oximetry has poor sensitivity, PPV, and NPV for detecting true monitoring status at the bedside. Teams intending to measure the actual use of pulse oximetry should be aware of the limitations of using active orders alone as an accurate measure of pulse oximetry monitoring.

\section{Acknowledgments}

We thank the NHLBI scientists who contributed to this project as part of the U01 Cooperative Agreement funding mechanism: Lora Reineck, MD, MS, Karen Bienstock, MS, and Cheryl Boyce, PhD.
We thank the Executive Council of the PRIS Network for their contributions to the early scientific development of this project. We thank the PRIS site investigators for their major contributions to the Eliminating Monitor Overuse (EMO) Study data collection. Each listed collaborator is a group author for the PRIS Network in this manuscript. Their names can be found in the online supplemental information.

Disclosures: The authors have no financial or other conflicts of interest to disclose.

Previous presentation of the information reported in the manuscript: Presented at the Pediatric Hospital Annual Meeting in Seattle, Washington, on July 26, 2019.

Funding: This study was funded by a Cooperative Agreement from the National Heart, Lung, and Blood Institute of the National Institutes of Health (5U01HL143475) awarded to Dr Bonafide. Dr Brady's contribution to this manuscript was supported by the Agency for Healthcare Research and Quality under Award Number K08HS23827. Dr Schondelmeyer's contribution to this manuscript was supported by the Agency for Healthcare Research and Quality under Award Number K08HS026763. Dr Bonafide's contribution to this manuscript was 
supported in part by the National Heart, Lung, and Blood Institute under award number K23HL116427. The funding organizations had no role in the design and conduct of the study; collection, management, analysis, and interpretation of the data; preparation, review, or approval of the manuscript; and decision to submit the manuscript for publication.

\section{References}

1. Ralston SL, Garber MD, Rice-Conboy E, et al. A multicenter collaborative to reduce unnecessary care in inpatient bronchiolitis. Pediatrics. 2016;137(1). https://doi.org/10.1542/peds.2015-0851

2. Mittal S, Marlowe L, Blakeslee S, et al. Successful use of quality improvement methodology to reduce inpatient length of stay in bronchiolitis through judicious use of intermittent pulse oximetry. Hosp Pediatr. 2019;9(2):73-78. https://doi.org/10.1542/hpeds.2018-0023

3. Quinonez RA, Coon ER, Schroeder AR, Moyer VA. When technology creates uncertainty: pulse oximetry and overdiagnosis of hypoxaemia in bronchiolitis. BMJ. 2017;358:j3850. https://doi.org/10.1136/bmj.j3850

4. Quinonez RA, Garber MD, Schroeder AR, et al. Choosing wisely in pediatric hospital medicine: five opportunities for improved healthcare value. J Hosp Med. 2013;8(9):479-485. https://doi.org/10.1002/jhm.2064

5. Ralston SL, Lieberthal AS, Meissner HC, et al. Clinical practice guideline: the diagnosis, management, and prevention of bronchiolitis. Pediatrics. 2014;134(5):e1474-e1502. https://doi.org/10.1542/peds.2014-2742

6. Principi T, Coates AL, Parkin PC, Stephens D, DaSilva Z, Schuh S. Effect of oxygen desaturations on subsequent medical visits in infants discharged from the emergency department with bronchiolitis. JAMA Pediatr. 2016;170(6):602-608. https://doi.org/10.1001/jamapediatrics.2016.0114

7. Cunningham S, Rodriguez A, Adams $T$, et al. Oxygen saturation targets in infants with bronchiolitis (BIDS): a double-blind, randomised, equivalence trial. Lancet. 2015;386(9998):1041-1048. https://doi.org/10.1016/s01406736(15)00163-4

8. McCulloh R, Koster M, Ralston S, et al. Use of intermittent vs continuous pulse oximetry for nonhypoxemic infants and young children hospitalized for bronchiolitis: a randomized clinical trial. JAMA Pediatr. 2015;169(10):898-904. https://doi.org/10.1001/jamapediatrics.2015.1746

9. Schuh S, Freedman S, Coates A, et al. Effect of oximetry on hospitalization in bronchiolitis: a randomized clinical trial. JAMA. 2014;312(7):712-718. https:// doi.org/10.1001/jama.2014.8637

10. Schroeder AR, Marmor AK, Pantell RH, Newman TB. Impact of pulse oximetry and oxygen therapy on length of stay in bronchiolitis hospitalizations. Arch Pediatr Adolesc Med. 2004;158(6):527-530. https://doi.org/10.1001/ archpedi.158.6.527

11. Rasooly IR, Beidas RS, Wolk CB, et al. Measuring overuse of continuous pulse oximetry in bronchiolitis and developing strategies for large-scale deimplementation: study protocol for a feasibility trial. Pilot Feasibility Stud. 2019;5:68. https://doi.org/10.1186/s40814-019-0453-2 